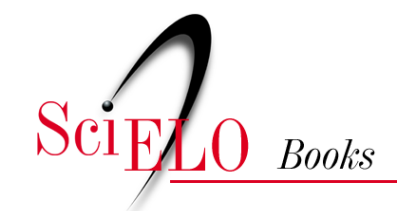

EDUFU

\title{
A problematicidade epistemológica do saber teatral
}

\author{
Adilson Florentino
}

FLORENTINO, A. A problematicidade epistemológica do saber teatral. In: FLORENTINO, A., and TELLES, N., eds. Cartografias do ensino do teatro [online]. Uberlândia: EDUFU, 2008, pp. 9-15. ISBN 978-85-7078-518-3. https://doi.org/10.7476/9788570785183.0002.

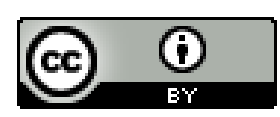

All the contents of this work, except where otherwise noted, is licensed under a Creative Commons Attribution 4.0 International license.

Todo o conteúdo deste trabalho, exceto quando houver ressalva, é publicado sob a licença Creative Commons Atribição $\underline{4.0}$.

Todo el contenido de esta obra, excepto donde se indique lo contrario, está bajo licencia de la licencia $\underline{\text { Creative Commons }}$ Reconocimento 4.0. 


\section{A PROBLEMATICIDADE EPISTEMOLÓGICA DO SABER TEATRAL}

\section{Adilson Florentino}

As discussões analisadas neste artigo são frutos de alguns insights, de caráter reflexivo, produzidos no cerne da minha pesquisa de doutoramento cujo eixo investigativo tenta problematizar as perspectivas paradigmáticas do ensino do teatro a partir das condições históricas de produção do Teatro como um campo de conhecimento, tencionado nas relações entre o saber científico e o saber escolar. Assim sendo, o Teatro como um campo de conhecimento representa um terreno epistemologicamente conflitado, no qual diferentes teorias, tendências e práticas lutam pelo modo como a realidade teatral deve ser produzida, reproduzida, significada e, sobretudo, interpretada.

O objetivo aqui elaborado é o de refletir sobre o problema do conhecimento teatral a partir do pressuposto de que o conhecimento do teatro não tem sido examinado sempre do mesmo modo, pois existem diferentes padrões de análise que orientam o modo de compreensão dos estudos investigativos sobre o teatro. Defende-se o pressuposto de que o problema não se situa na diversidade de paradigmas, mas na possibilidade de estabelecer critérios homogêneos de análise a respeito do conhecimento teatral.

Falar do conhecimento do teatro é o mesmo que interrogar-se acerca do teatro como objeto de conhecimento, o que equivale a formular uma dupla indagação:

a) O que é necessário conhecer para entender e dominar o campo do teatro ou quais são os componentes constituidores do fenômeno teatral que têm de ser dominados para entender este fenômeno?

b) Como se dá o conhecimento desse campo ou que garantias de credibilidade se pode obter acerca do campo do teatro?

O objetivo, quando se analisa o conhecimento do teatro, é o de estabelecer um eixo de interpretação que nos permita, com critério lógico, compreender a distinta consideração que o conhecimento do teatro possui. Para isso, é preciso tentar descrever as propriedades que permitem caracterizar os diferentes momentos de constituição do teatro como objeto de conhecimento. O objetivo não é a produtivi- 
dade existente em cada um desses momentos; o que preocupa não é a quantidade de investigações realizadas, mas, sobretudo, saber como é considerado o teatro como objeto de conhecimento em diferentes investigações.

$\mathrm{O}$ interesse deve recair mais sobre as análises dos pressupostos que permitem entender, de certa perspectiva, o teatro como objeto de conhecimento. A fecundidade da hipótese que aqui está sendo colocada aponta para os conceitos e as precisões terminológicas que são, sucessivamente, estabelecidas. O que interessa, especificamente, é o entendimento da própria transformação do teatro como objeto de conhecimento e sua progressiva inserção no contexto estudado. Interessa saber, portanto, quais são as propriedades que definem, em diversos momentos, o teatro como objeto de conhecimento e como se dá a justificação de que determinada investigação é a que se deve proceder para a análise do objeto em questão.

Esse tipo de questão recebe a denominação, segundo Khun ${ }^{1}$ de paradigma de investigação. No trabalho de Khun acerca da estrutura das revoluções científicas, é possível detectar dezenas de usos diferenciados do termo paradigma. Os paradigmas podem ser entendidos como marcos de interpretação ou modos de pensar acerca de algo; em si mesmos, eles não constituem teorias, uma vez que o pesquisador se compromete ou assume um único marco ou modo específico, o que pode conduzir ao desenvolvimento de teorias.

A preocupação básica desta reflexão é a de estabelecer o marco de interpretação que permita compreender a distinta condição de possibilidade do conhecimento teatral. Nesse sentido, o ponto de partida está centrado na convicção de que não tem existido a mesma consideração para a função teatral, porque o conhecimento do teatro não possui sempre a mesma significação, entendida como a capacidade que esse conhecimento possui de responder aos problemas das práticas teatrais.

Assim sendo, os critérios estabelecidos para elaborar o marco de interpretação permitem, segundo o tipo de respostas, configurar uma concepção específica de teatro e, portanto, um modo peculiar de relacionar a teoria e a prática.

Em analogia com a historicidade de outros saberes, as práticas investigativas do teatro se distinguem em vários campos e tentam responder às seguintes questões:

1) a consideração do teatro como objeto de conhecimento;

2) o tipo de conhecimento a ser obtido pelo saber teatral;

3) o modo de resolver o ato de intervenção;

4) a possibilidade ou não do estudo "científico", das ciências do espetáculo ou da teatrologia.

Cada uma dessas questões cria um padrão de justificativa da ação teatral e estabelece os limites e as potencialidades de resolução da problemática do conhecimento teatral. Cada uma dessas questões elabora um tipo de discurso em que a relação teoria-prática se dá de um modo diferente. O discurso teatral, a função teatral e a prática teatral se relacionam de modos diferentes em cada uma das questões acima porque as respostas produzem distintas visões sobre o teatro, ou seja, produzem diferentes concepções de teatro.

\footnotetext{
${ }^{1}$ KHUN, Thomas. La estructura de las revoluciones cientificas. 2. ed. Madrid: Fondo de Cultura
} Económica, 1995. 320 p. 
As concepções podem funcionar como paradigmas, isto é, como marcos interpretativos assumidos pelo pesquisador e podem produzir teorias sobre a função teatral, o discurso e a prática teatrais. Como pressupostos de investigação, as concepções funcionam como uma antecipação daquilo que se deseja conseguir e orienta a observação do fenômeno teatral na perspectiva daquilo que adquire um sentido no interior de uma específica perspectiva.

Um ponto curioso dessa questão é que a perspectiva teatral, muitas vezes, não se encontra explicitada no exercício da investigação e, contraditoriamente, dela depende o sentido do que é afirmado e negado sobre o teatro. Talvez, por isso, cada concepção redefine o campo de conhecimento do teatro, produz novos valores e reformula os já existentes.

Cada concepção sobre o teatro deve exigir rigor lógico e significação. O rigor lógico se define como uma das características defendidas com exclusividade em uma dada concepção e, ao mesmo tempo, determina um modo distinto de entender o teatro como objeto de conhecimento. Por sua vez, a significação se define como a capacidade que tem a representação do conhecimento teatral, resultante de uma lógica, de organizar historicamente a produção desse conhecimento. A significação possibilita identificar a tendência do conhecimento teatral de uma determinada pesquisa, de um livro sobre o teatro ou até mesmo de uma prática teatral concreta. $\mathrm{O}$ fato de serem incluídos em uma tendência pressupõe a defesa de uma determinada concepção de teatro como objeto de conhecimento.

Cada tendência tem um marco referencial que permite uma resposta específica às questões de análise das investigações teatrais. Precisamente por isso, pode-se dizer que tudo o que afeta o tema de estudo (do teatro), desde que não contradiga àquelas respostas, cabe no território de uma dada tendência. Por esta razão, as tendências não se definem nem por um método nem por uma concepção de ciência, nem por uma filosofia de vida. Numa tendência, cabem todos esses elementos, desde que sejam compatíveis com o marco referencial estabelecido. O que há de variar em cada um dos elementos acima descritos são as finalidades que defendem sobre o teatro.

O teatro é um campo amplo e profundo para investigar; sua riqueza de situações, teorias, práticas e processos formam parte de um material que permite iniciar distintas investigações. Junto desse material encontramos a complexidade dos fenômenos teatrais que só podem ser captados mediante investigações realizadas em algumas perspectivas e, desse modo, o estudo heurístico do teatro possibilita uma ampla variedade de modos de investigação.

Não existe acordo na classificação dos métodos e variações de cada modo de investigação no campo teatral. O método pode ser colocado a serviço de variados tipos de objetivos, nos mais diferentes ramos do saber e, no seu interior, com diversas perspectivas e características. As diferenças entre os métodos de investigação não radicam no fato de que podem ser concebidos como vias alternativas para alcançar o mesmo fim ou responder de maneira diferente a mesma pergunta ou questão. $O$ que distingue radicalmente os métodos entre si não são os procedimentos que aplicam, mas sim, fundamentalmente, o tipo de questões que pretendem ou podem resolver, assim como pressupostos e postulados básicos que determinam e especificam os critérios de evidência e a interpretação das respostas obtidas. 
A diversidade metodológica da investigação teatral responde à existência de vários paradigmas que, por sua vez, estão enraizados em algumas tradições disciplinares, tais como a Semiologia. O espetáculo teatral está repleto de significação e se constitui numa constelação de signos complexos ${ }^{2}$. Na perspectiva da Semiótica, De Marinis assinala que esta área de estudos relaciona-se à dimensão central do objeto teórico do teatro que se revela tipicamente como sendo um fenômeno de significação e de comunicação. No cerne desse debate, mas a partir de uma outra vertente, merece consideração a análise que Ubersfeld empreende em relação à problematização da questão do signo no teatro, argumentando que a relação texto-representação se organiza partindo da hipótese que afirma que o fato teatral se constitui como relação entre dois conjuntos de signos: verbais ou não verbais ${ }^{3}$.

No entanto, é De Marinis que defende o que ele denomina de teatrologia ou ciências do teatro que se reveste de um caráter transdisciplinar, a fim de permitir estudar o complexo mundo do teatro. A complexidade dos fenômenos teatrais exige a operação de enfoques plurimetodológicos, conforme afirma Pavis, pois somente através de enfoques flexíveis pode ser possível captar e aprofundar a efetivação do objeto-espetáculo rumo ao objeto-teatro ${ }^{4}$.

Assim sendo, há possibilidade de se pensar na investigação teatral entendendo-a dentro do sistema aberto que as ciências do teatro formam. O teatro é um campo de estudos que contém fenômenos, problemas e processos que constituem em si mesmos o material para realizar investigações em diferentes perspectivas.

Todavia, o teatro não é uma ciência no sentido daquelas ciências discutidas por Feyerabend, Khun, Lakatos e Popper. Para Ubersfeld, o teatro é uma arte do paradoxo, cujos fios paradoxais se entrelaçam na relação entre texto e representação, a primeira contradição inscrita na arte do teatro ${ }^{5}$.

Nas considerações do debate em torno da arte, foi seguramente Adorno ${ }^{6}$ quem confrontou a análise da natureza dela como conhecimento, apontando o conteúdo de verdade que caracteriza e fundamenta, em seu aspecto mais essencial, toda a obra de arte. A partir da perspectiva que a sua teoria estética propõe, a característica da arte contemporânea não pode ser senão a impossibilidade de transparência. De fato, o caráter enigmático da obra de arte, sob o viés lingüístico, consiste naquilo que as obras dizem e não no que ocultam. A arte, como forma de ocultamento, atua através de seu aparente contrário: o jogo da hipervisibilidade, da hiperdemonstração. Esse procedimento consiste, segundo o próprio Adorno, que aquilo que a obra de arte tenta ocultar se manifesta, porque ao se manifestar se oculta. Daí que em todos os seus momentos mais ambiciosos a atuação artística se situa mediante um paradoxo desvelamento das convenções e recursos utilizados.

\footnotetext{
${ }^{2}$ GUINSBURG, Jaco; COELHO NETO, J. Teixeira; CARDOSO, Reni Chaves. Semiologia do teatro. 2. ed. São Paulo: Perspectiva, 2003. 380 p.

${ }^{3}$ MARINIS, Marco. Comprender el teatro: el lineamientos de una nueva teatrología. Buenos Aires: Galerna, 1997. 287 p.; UBERSFELD, Anne. Para ler o teatro. São Paulo: Perspectiva, 2006. 202 p.

${ }^{4}$ MARINIS, 1997; PAVIS, Patrice. A análise dos espetáculos. 2. ed. São Paulo: Perspectiva, 2003. $323 \mathrm{p}$.

${ }^{5}$ FEYERABEND, Paul. Contra o método. 2. ed. Lisboa: Relógio D’Água, 1997. 364 p.; KHUN, 1995; LAKATOS, Imre. Historia de las ciencias y sus reconstruciones racionales. 2. ed. Madrid: Tecnos, 1987. 188 p.; POPPER, Karl. A lógica da pesquisa científica. 2. ed. São Paulo: Cultrix, 1980. 256 p.; UBERSFELD, 2006.

${ }_{6}$ ADORNO, Theodor. Teoria estética. 2. ed. Lisboa: Edições 70, 2006. 294 p.
} 
Desse ponto de vista, o conhecimento que é arte não é discursivo, pois sua verdade não é reflexa de um objeto. Impõe-se ao artista mais que a exposição de resultados ou conclusões ao expor o próprio caráter problemático do pensar e do conhecer. A verdade da obra de arte não pode ser outra coisa do que a comunicação do incomunicável, a manifestação explosiva da consciência oprimida. Para Adorno, as obras de arte são evidências do inevidente, a compreensão do incompreensível, pois em nenhum momento cabe à tarefa da filosofia da arte elucidar o incompreensível, senão tratar de entender a própria incompreensibilidade.

A arte seria capaz, segundo Kant ${ }^{7}$ de servir de ponte de mediação entre dois eixos contrapostos: a natureza e a liberdade, entre as funções intelectuais e a atividade moral, a fim de garantir uma unidade harmônica no ser humano. A espontaneidade da razão é levada ao terreno da sensibilidade, cobrindo o imenso abismo existente entre ambas.

Schiller ${ }^{8}$, o fundador da educação estética como disciplina, considerava-a como o fundamento principal da educação humana, como a essência da própria educação ao entendê-la como mediação entre racionalidade e sensibilidade. Para Schiller, a arte constitui uma síntese de natureza e liberdade, realidade e identidade, entre matéria e forma.

No entanto, Habermas ${ }^{9}$ propõe que a experiência estética não deve ser capaz de renovar as interpretações das necessidades à luz do que percebemos do mundo, pois deverá ser capaz, também, de intervir na articulação cognitiva das experiências normativas, transformando o modo como os discursos estético, prático-moral e factual se referem uns aos outros. Habermas optou em considerar a obra de arte como uma possível função de mediação, sustentando que as experiências estéticas, as interpretações cognitivas e as regulações normativas não são independentes entre si. Isso significa pressupor que os discursos estético, prático-moral e factual não estão separados entre si por um abismo, mas estão relacionados de múltiplas formas.

Toda essa discussão de caráter filosófico está aqui apresentada para justificar a importância e o aprofundamento que a questão artística e, mais especificamente, a questão teatral evocam no que concerne à problemática do conhecimento. O que nos interessa neste trabalho é capturar os nexos existentes entre teatro e ciência, a fim de localizar uma possível epistemologia do saber teatral. O pressuposto fundamental por nós defendido é que a metodologia de investigação teatral possui um vínculo referencial com o conhecimento científico.

A teoria geral do teatro parte de uma teoria do texto dramático que desemboca na teoria do espaço cênico sob as perspectivas de diferentes propostas interdisciplinares. É exatamente essa disciplina do conhecimento científico-artístico que De Marinis denomina teatrologia. É nesse caráter epistemológico que a vinculação da ciência com a arte tem seus laços mais estreitos.

Assumir o estudo do teatro ou empreender uma investigação sobre o teatro é correr o risco de se deparar com a seguinte questão: como ciência, o estudo do teatro não é totalmente objetivo, pois o seu caráter é explicitamente subjetivo e tem

\footnotetext{
7 KANT, Immanuel. Observaciones acerca del sentimiento de lo bello y de lo sublime. 2. ed. Madrid: Alianza, 1990. 304 p.

${ }^{8}$ SCHILLER, Friedrich. A educação estética do bomem. São Paulo: Iluminuras, 1990. 164 p.

9 HABERMAS, Jürgen. O discurso filosófico da modernidade. São Paulo: M. Fontes, 2002. 540 p.
} 
uma amplíssima vantagem de ser uma ciência do espírito humano, mesmo que tal afirmativa possa correr o risco de sua radicalidade na medida em que se tece a indagação de qual ciência não é humana.

Para fundamentar esse desiderato, parto da premissa de que o teatro é uma manifestação cultural e artística, de caráter cênico e que possui especificidades próprias circunscritas nos planos sintático, semântico e pragmático. O estudo do teatro constitui um âmbito de realidade instalado numa esfera de conhecimento, contendo um objeto próprio e uma cientificidade específica que tentam definir um estatuto epistemológico para a construção de um discurso teórico e disciplinar que desenvolve o seu edifício acadêmico e institucional de modo a ser capaz de problematizar, formalizar e sistematizar aquilo que denominamos teatro.

É neste momento que a vinculação com a ciência se torna mais evidente, pois a investigação cria um amplo espectro de possibilidades para o nosso objeto de estudo que, necessariamente, requer um procedimento analítico e interpretativo. Tal procedimento exige, por sua vez, como critério para a produção do conhecimento, o uso da heurística, da epistemologia e da hermenêutica.

Sobretudo nas últimas décadas, o campo da investigação teatral tem crescido muito no Brasil. Houve diversificação das linhas de pesquisa em teatro, como também houve a ampliação dos paradigmas e da adoção de abordagens metodológicas que utilizam as técnicas de análise de dados, muito mais complexas e sofisticadas; para isso, recomendo a leitura do livro Metodologias de pesquisa em artes cênicas, organizado por Carreira e outros ${ }^{10}$.

Nesse sentido, devemos aglutinar esforços em relação à produção do conhecimento em teatro apontando uma alternativa de ação urgente e necessária: a formação de professores-pesquisadores de teatro. Entendemos que o professor-pesquisador de teatro deve estar atento ao contexto contemporâneo, observar os limites impostos pelas metodologias adotadas, produzir novas formas de aprofundar os conhecimentos sem sujeitar-se a esquemas preconcebidos; tudo isso com o objetivo de melhorar a teoria e a prática teatrais e de incidir na realidade histórico-social.

Por fim, gostaríamos de enfatizar que a noção do saber-fazer artístico comporta, em si, uma segunda premissa fundacional para este trabalho reflexivo: a reivindicação de uma epistemologia própria para a investigação levada a cabo por pesquisadores, professores e artistas de teatro. Muito mais que propor um rótulo de designação historicista, interessa questionar ativamente o território do teatro como lugar privilegiado de experimentação e interrogação que se alarga para âmbitos não estritamente reservados à pesquisa estética. Trata-se, portanto, de uma proposta de abordagem de amplitude alargada, uma opção pela inter/transdisciplinaridade que, ao ser capaz de gerar esta espécie de epistemologia para o lugar da interrogação teatral, terá a capacidade de refletir — não por inclusão, mas por alargamento - outras disciplinas, com particular ênfase naquelas que questionam diretamente o envolvimento das realidades com que o teatro se contextualiza para existir.

${ }^{10}$ CARREIRA, André et al. (Org.). Metodologias de pesquisa em artes cênicas. Rio de Janeiro: 7 Letras, 2006. $159 \mathrm{p}$. 


\section{REFERÊNCIAS}

ADORNO, Theodor. Teoria estética. 2. ed. Lisboa: Edições 70, 2006.

CARREIRA, André et al. Metodologias de pesquisa em artes cênicas. Rio de Janeiro: 7 Letras, 2006.

DE MARINIS, Marco. Comprender el teatro: el lineamientos de una nueva teatrología. Buenos Aires: Galerna, 1997.

FEYERABEND, Paul. Contra o método. 2. ed. Lisboa: Relógio D’Água, 1997.

GUINSBURG, Jaco; COELHO NETO, J. Teixeira; CARDOSO, Reni Chaves. Semiologia do teatro. 2. ed. São Paulo: Perspectiva, 2003.

HABERMAS, Jürgen. O discurso filosófico da modernidade. São Paulo: M. Fontes, 2002.

KANT, Immanuel. Observaciones acerca del sentimiento de lo bello y de lo sublime. 2. ed. Madrid: Alianza, 1990.

KHUN, Thomas. La estructura de las revoluciones cientificas. 2. ed. Madrid: Fondo de Cultura Económica, 1995.

LAKATOS, Imre. Historia de las ciencias y sus reconstruciones racionales. 2. ed. Madrid: Tecnos, 1987.

PAVIS, Patrice. A análise dos espetáculos. 2. ed. São Paulo: Perspectiva, 2003.

POPPER, Karl. A lógica da pesquisa científica. 2. ed. São Paulo: Cultrix, 1980.

SCHILLER, Friedrich. A educação estética do bomem. São Paulo: Iluminuras, 1990.

UBERSFELD, Anne. Para ler o teatro. São Paulo: Perspectiva, 2006. 